\title{
Löffler's Endocarditis: First Report of Successful Mitral and Tricuspid Valve Replacements in a Patient with Long-Standing Hypereosinophilia
}

Neil P. Naik, MB, BCh, BAO

Sahar Iqbal, MBBS, MSc, FRCPC, FACP

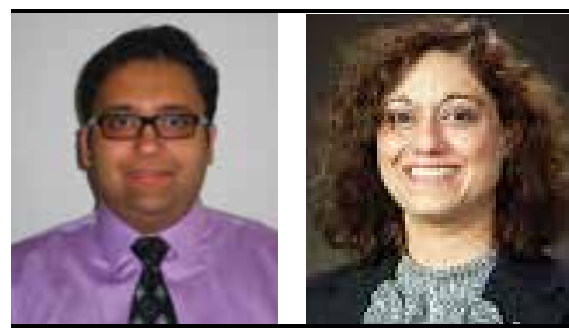

About the Authors

Neil P. Naik, MB, BCh, BAO, is a CCFP candidate at Memorial University of Newfoundland, St. John's, Newfoundland and Sahar Iqbal, MBBS, MSc, FRCPC, FACP, is an assistant professor of internal medicine at Memorial University of Newfoundland, St. John's, Newfoundland. Correspondence may be directed to sjiqbal@mun.ca.

\section{Summary}

Löffler's endocarditis is a condition that occurs in patients with hypereosinophilic syndrome (HES). First described in 1975, HES is a relatively new syndrome that is characterized by elevated eosinophils with end organ damage. Hypereosinophilia is defined as elevated eosinophils of 1.5 $\mathrm{x} 10^{9} / \mathrm{L}$ for at least one month, or tissue involvement as evidenced by bone marrow section with $20 \%$ eosinophils, tissue infiltration, and/or deposition of eosinophil granule proteins in tissue. Prevalence of HES in the United States is estimated to be $0.36-6.3 / 100,000$ people, of which Löffler's endocarditis represents only a fraction of cases. We present a case where a patient presented with palpitations and shortness of breath, with a background of chronically elevated eosinophils. HES was previously diagnosed in this patient due to persistently elevated eosinophils with lung damage (Löffler's syndrome). On biopsy, she was found to have endomyocardial fibrosis with a thickened endocardium secondary to eosinophils. Echocardiogram showed moderate to severe regurgitation in both mitral and tricuspid valves due to regurgitation secondary to fibrosis. She subsequently underwent a successful dual valve replacement. This is the first case, to our knowledge, where a dual valve replacement was performed successfully in a patient with Löffler's endocarditis.

\section{Résumé}

L'endocardite fibroblastique de Löffler survient au cours du syndrome hyperéosinophilique (SHE). Défini en 1975, le SHE, relativement nouveau, se caractérise par une élévation des éosinophiles et des lésions viscérales. L'hyperéosinophilie se dit d'un taux d'éosinophiles de $1,5 \times 10^{9} / 1$ pendant un mois à tout le moins ou de l'infiltration tissulaire comme en témoigne la présence de $20 \%$ d'éosinophiles dans la moelle osseuse, l'infiltration de tissus par les éosinophiles ou l'accumulation de granulations d'éosinophiles dans des tissus. L'on estime que la prévalence du SHE aux ÉtatsUnis est de 0,36 à 6,3 par 100000 personnes; l'endocardite de Löffler ne se produit que dans une fraction de ces cas. Le cas que nous décrivons ici est celui d'une femme présentant des palpitations et de l'essoufflement sur fond d'élévation chronique des éosinophiles. On lui a déjà diagnostiqué un SHE sur le motif de la persistance de l'hyperéosinophilie et de la présence de lésions pulmonaires (syndrome de Löffler). À la biopsie, on découvre une fibrose endomyocardique accompagnée d'un épaississement de l'endocarde due aux éosinophiles. L'échocardiogramme révèle une régurgitation mitrale et tricuspidienne modérée à grande secondaire à la fibrose. La patiente a subi une chirurgie de remplacement valvulaire, intervention réussie. Pour autant que nous sachions, il s'agit du premier cas de remplacement valvulaire double réussi chez un patient présentant une endocardite de Löffler. 


\section{Introduction}

Löffler's endocarditis, first described in 1936, is a syndrome within the umbrella of hypereosinophilic syndromes (HES). It is characterized by elevated eosinophils, which penetrate cardiac myocytes, leading to fibrotic thickening of portions of the heart. ${ }^{1}$ HES was originally presented in 1975 and was initially proposed to have three defining features: serum eosinophilia greater than 1500 cells per microliter over a six-month period, no apparent cause to explain the rise in eosinophil count, and signs/symptoms of end organ damage secondary to the hypereosinophilia. ${ }^{2}$ However, the definition has since changed to include patients receiving treatment before the full six-month period of hypereosinophilia (HE) has lapsed and has further included patients with known causes of $\mathrm{HE}^{3}{ }^{3}$ We present a patient who, for all intents and purposes, had idiopathic Löffler's endocarditis according to the originally proposed definition.

\section{Case}

A 44-year-old woman presented with a two-week history of palpitations, shortness of breath on exertion, and ST depression and T-wave inversion across multiple leads on ECG, on a background family history of Lynch syndrome. Her medical history was significant for 10-year history of pulmonary eosinophilia with asthma-like symptoms, osteoporosis, and environmental allergies. She denied any smoking or alcohol use. On examination, the patient appeared flushed, but not in distress. Her heart rate was 130 beats per minute, with normal heart sounds, an elevated jugular venous pressure, and bilateral lower limb pitting edema. Decreased breath sounds were auscultated in the lower lung lobes, with bilateral crackles on deep inspiration. Palpation of her abdomen produced mild right upper quadrant tenderness.

Investigations were extensive, but her leukocyte count was $11.8 \times 109 / \mathrm{L}$, with an elevated absolute eosinophil count of 2.9 x 109/L. Her hemoglobin level, lactate dehydrogenase, tryptase, and creatinine kinase were 123 grams $/ \mathrm{L}, 426$ units $/ \mathrm{L}, 2.4 \mathrm{mcg} / \mathrm{L}$, and 253 units/L, respectively. Her troponin was positive at 0.34 $\mathrm{mcg} / \mathrm{L}$. Her erythrocyte sedimentation rate was $2 \mathrm{~mm} /$ hour; however, her rheumatoid factor and C-reactive protein were both positive at $36.3 \mathrm{~K} \mathrm{UI} / \mathrm{L}$ and $9.93 \mathrm{mg} / \mathrm{L}$, respectively. Initial gamma-glutamyl transpeptidase was elevated at $159 \mathrm{mcg} / \mathrm{L}$. Connective tissue disease and vasculitis screen was found to be negative for antinuclear antibody, perinuclear and cytoplasmic anti-neutrophil cytoplasmic antibody.

Transthoracic echocardiogram (TTE) on post-admission Day 1 showed significant dilatation of the left and right atria, at approximately $4.5-5 \mathrm{~cm}$ each, and thickening of the ventricles bilaterally at the apex, measuring $2.1 \mathrm{~cm}$. The interventricular septum and posterior walls were within normal limits. Contractility was $55 \%$, with decreased movement at the ventricular apex. There was limited atrial annulus motion consistent with a restrictive pattern. The mitral and tricuspid valves had a normal echogenicity; however, there was moderate to severe $3+$ mitral insufficiency and moderate $3+$ tricuspid insufficiency. Interventricular thrombus was ruled out on magnetic resonance imaging (MRI), and endocardial hypertrophy was confirmed on a follow-up TTE (Figure 1). Computed tomography (CT) scan 11 days post-admission showed a small pericardial effusion with contrast accumulation in the left ventricular apex, demonstrating an isodense mass surrounding a central hypoattenuated area inconsistent with an aneurysm or a thrombus.

Cardiac catheterization showed infiltrative processes in both ventricles. The left ventricle was normal, with mild "sluggishness" in the inferior wall, and the right ventricle was nearly obliterated. Biopsies revealed endomyocardial fibrosis (Figure 2) with diffuse eosinophilic infiltrate (Figure 3).

Prednisone $40 \mathrm{mg}$ daily was prescribed and subsequent blood work demonstrated a decreasing eosinophil count. A bone marrow biopsy two months later demonstrated no dyserythropoiesis, with normal distribution of leukocyte subsets. There was no evidence of eosinophils in the peripheral blood. Immunologic, cytogenetic, and molecular studies demonstrated no underlying myeloproliferative disorders. The myeloproliferative cancer gene mutation, JAK2-v617F, was negative.

A mechanical mitral and bioprosthetic tricuspid valve replacement were performed with removal of endomyocardial fibrosis from both ventricles four months after initial presentation. Subsequent echocardiograms showed normal functioning valves and no residual interventricular fibroses. She is currently on a tapering dose of prednisone, with the goal of maintaining remission, while minimizing the risk of glucocorticoid-induced osteoporosis.

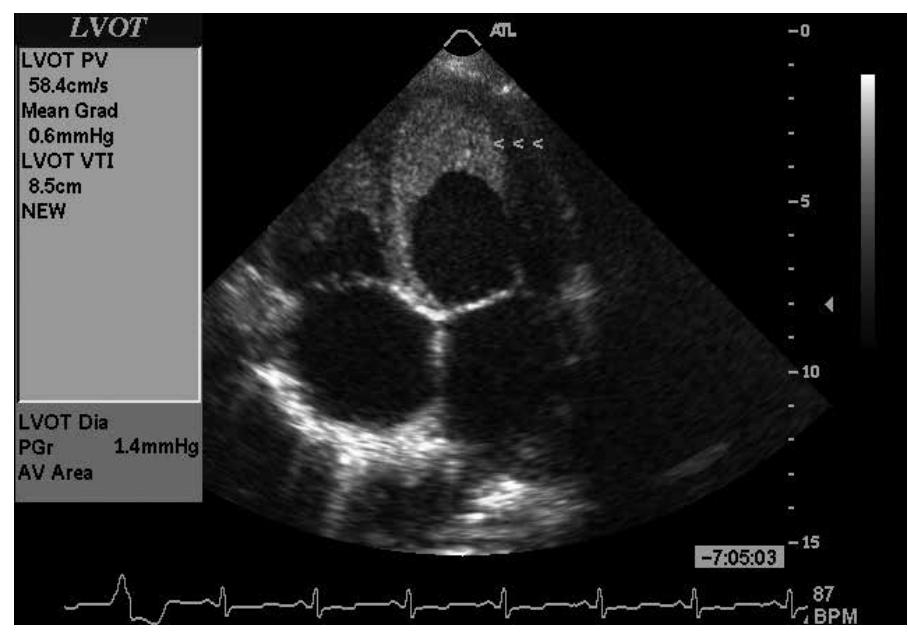

Figure 1. Transthoracic echocardiogram demonstrating endocardial thickening of the ventricles. 


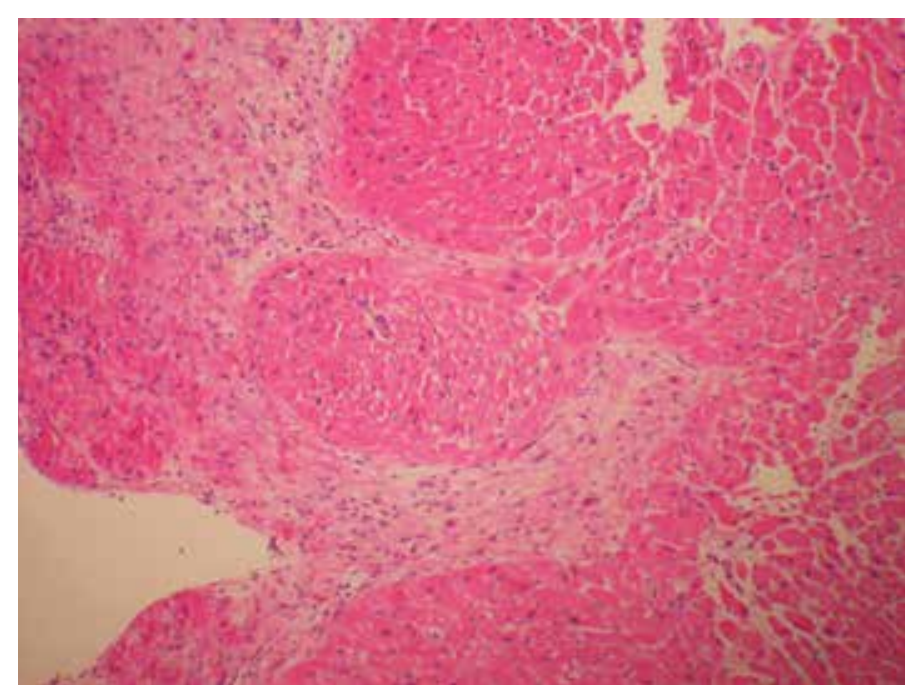

Figure 2. Histological sample of biopsy showing endomyocardial fibrosis and layering of the thick endocardium (haemotoxylin and eosin stain).

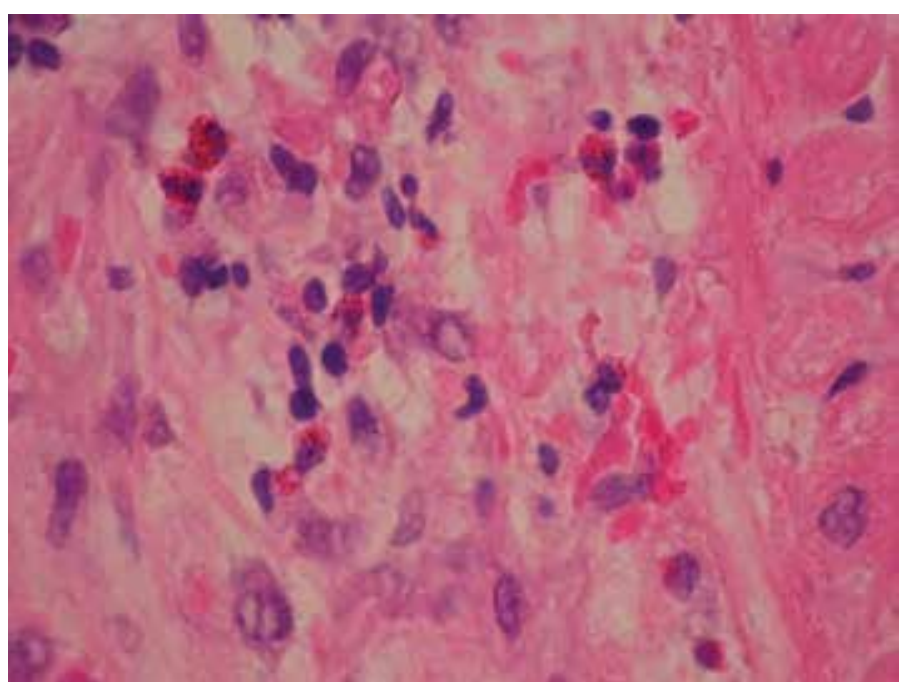

Figure 3. Eosinophils (purple) in the native mitral valve (haemotoxylin and eosin stain).

\section{Discussion}

This patient was diagnosed with idiopathic Löffler's endocarditis as a result of having long-standing eosinophilia without an identified etiology associated with objective end organ damage.

The new definition of HES is more encompassing than the original definition proposed by Chusid and colleagues in 1975. ${ }^{2}$ A panel of experts in the 2011 Working Conference on Eosinophil Disorders and Syndromes defined HE by the presence of eosinophilia greater than $1.5 \times 10^{9} / \mathrm{L}$ for at least one month or tissue involvement as evidenced by bone marrow section with $20 \%$ eosinophils, tissue infiltration, and/or deposition of eosinophil granule proteins in tissue. ${ }^{3}$ A principal reason for this revision was to expedite timely treatment rather than having to wait six months to confirm a diagnosis. HES, accordingly, is defined as HE with eosinophil-mediated organ damage or dysfunction. It may include situations where the etiology for the eosinophilia is known.

HES can be further sub-classified as primary, secondary, or complex. ${ }^{4}$ Primary HES results from underlying stem cell, myeloid, or eosinophilic neoplasm causing clonal expansion. Secondary HES is a reactive type of HE caused by parasites or lymphomas, etc., causing an overproduction of eosinophilopoetic cytokines. Complex HES is used to describe patients who cannot be classified under primary or secondary HES but who present with clinical stigmata of HES. Eosinophils tend to be polyclonal in these cases. Some experts have called for the elimination of the classification of idiopathic types of HES altogether, because causes can usually be found with extensive investigation; however, determining the underlying cause might only be of academic value and can be expensive. ${ }^{4}$

The true prevalence of HES is unknown but believed to be quite rare. As a result, Löffler's endocarditis is rare as well. One study estimated the prevalence of HES to be about 0.36$6.3 / 100,000$ in the US; however, this number was determined by extrapolating from the Surveillance, Epidemiology, and End Results (SEER) program using estimates from literature. ${ }^{5}$ Furthermore, the lack of a specific International Classification of Diseases, Ninth Edition (ICD-9) code for HES makes determining the prevalence even more difficult. ${ }^{5}$ Estimated 10 -year survival is less than $50 \%$ in patients with HES and less than $30 \%$ in those with endomyocardial fibrosis. ${ }^{6}$ Some $60 \%$ of patients with HES tend to have cardiac involvement, with endomyocardial fibrosis being the main finding, sometimes with valve leaflet vegetations leading to progressive scarring and restricted valve movement. ${ }^{7}$ Classic history and physical signs are highlighted in Table 1.

Table 1. Key Points Learned From This Case

\section{Key Points}

- Do not wait 6 months to confirm hypereosinophilia to begin treatment for Löffler's endocarditis.

- The nidus can typically be identified; however, if the common reversible causes are ruled out, further specific testing may not necessarily be clinically useful.

- Hypereosinophilic syndrome is a rare syndrome, with Löffler's syndrome representing a smaller subgroup.

- It is imperative to reduce long-term cardiac sequelae with the use of angiotensin converting enzyme (ACE)-inhibitors and B-blockers. Anticoagulation should be considered if a thrombus is identified or if valve replacements are performed. 
Table 2. History and Physical Examination Findings in Patients with Löffler's Endocarditis

\begin{tabular}{|l|l|}
\hline \multicolumn{1}{|c|}{$\begin{array}{c}\text { Findings on History } \\
\text { (generally non-specific) }\end{array}$} & Findings on Exam \\
\hline - Weight loss & \\
- Fever & - Peripheral edema \\
- Rash & - Arrhythmias \\
- Symptoms suggestive of & - Tachycardia \\
congestive heart failure & - Cardiomegaly \\
o Shortness of breath & o Displaced apex beat \\
o Cough & o Heaves \\
o Dizziness & - Murmurs \\
& o Dependent on valve affected \\
& by fibrosis \\
& o Difficult to ascertain on \\
& physical examination specific \\
& murmurs due to multi-valve \\
& fibrosis \\
& - Findings suggestive of \\
thromboembolic event \\
o Stroke \\
o Finger/toe tip ulcers \\
\end{tabular}

Treatment is a multi-step process that involves treating the underlying disease, if one exists, and then tackling the elevation in eosinophils. Eosinophils have been postulated to cause damage via degranulation. ${ }^{1}$ Thus, normalizing the eosinophil level has been the current mainstay of treatment through corticosteroid treatment, as in our case. In the case of corticosteroid-resistance, trials of myelosuppresive agents (i.e. hydroxyurea), interferon-gamma, and tyrosine kinase inhibitor imatinib have been shown to work. Imatinib has been shown to cause rapid regression of eosinophilic proliferation and resolution of hypereosinophilia. It is even proposed as firstline treatment due to its effectiveness, especially if the FIP1L1/ PDGFA fusion gene is detected. ${ }^{8}$

Guidelines for the Prevention of Chronic Heart Failure have recommended that prevention of ventricular re-modelling secondary to HE should be considered to reduce longterm sequelae, using angiotensin converting enzyme (ACE) inhibitors and beta blockers. ${ }^{9}$ Anticoagulation may be started if evidence of thrombus is seen, in order to reduce embolic events. The use of a bioprosthetic valve in lieu of a prosthetic mechanical valve in the tricuspid replacement is due to previous literature describing exaggerated platelet aggregation causing thrombotic complications. ${ }^{10,11}$

Several case reports have been published, detailing various presentations Löffler's endocarditis. Many have similar presentations to our case, with right-sided heart failure and possible thrombi in the ventricles. However, to the best of our knowledge, this case is the first in reporting both a mitral and tricuspid valve presentation with successful treatment involving atrio-ventricular valve replacements.

\section{References}

1. Benezet-Mazuecos J, de la Fuente A, Marcos-Alberca P, et al. Loeffler endocarditis: what have we learned? Am J Hematol 2007;82:861-2. Epub 2007 June 19

2. Chusid MJ, Dale DC, West BC, et al. The hypereosinophilic syndrome: analysis of fourteen cases with review of the literature. Medicine (Baltimore) 1975;54:1-27. Epub 1975 Jan 1.

3. Valent P, Klion AD, Horny HP, et al. Contemporary consensus proposal on criteria and classification of eosinophilic disorders and related syndromes. J Allergy Clin Immunol 2012;130:607-12e9. Epub 2012 March 31.

4. Gleich GJ, Leiferman KM. The hypereosinophilic syndromes: current concepts and treatments. Br J Hematol 2009;145:271-85. Epub 2009 Feb 27.

5. Crane MM, Chang CM, Kobayashi MG, et al. Incidence of myeloproliferative hypereosinophilic syndrome in the United States and an estimate of all hypereosinophilic syndrome incidence. J Allergy Clin Immunol 2010;126:179-81. Epub 2010 July 7.

6. Chao BH, Cline-Parhamovich K, Grizzard JD, et al. Fatal Loeffler's endocarditis due to hypereosinophilic syndrome. Am J Hematol 2007;82:920-3. Epub 2007 May 31.

7. Sen T, Ponde CK, Udwadia ZF. Hypereosinophilic syndrome with isolated Loeffler's endocarditis: complete resolution with corticosteroids. J Postgrad Med 2008;54:135-7. Epub 2008 May 16.

8. Rotoli B, Catalano L, Galderisi M, et al. Rapid reversion of Loeffler's endocarditis by imatinib in early stage clonal hypereosinophilic syndrome. Leuk Lymphoma 2004;45:2503-7. Epub 2004 Dec 29.

9. Hunt SA, Abraham WT, Chin MH, et al. ACC/AHA 2005 Guideline Update for the Diagnosis and Management of Chronic Heart Failure in the Adult: a report of the American College of Cardiology/American Heart Association Task Force on Practice Guidelines (Writing Committee to Update the 2001 Guidelines for the Evaluation and Management of Heart Failure): developed in collaboration with the American College of Chest Physicians and the International Society for Heart and Lung Transplantation: endorsed by the Heart Rhythm Society. Circulation 2005;112:e154-235. Epub 2005 Sep 15.

10. Watanabe K, Tournilhac O, Camilleri LF. Recurrent thrombosis of prosthetic mitral valve in idiopathic hypereosinophilic syndrome. J Heart Valve Dis 2002;11:447-9. Epub 2002 June 12.

11. Hii MW, Firkin FC, MacIsaac AI, et al. Obstructive prosthetic mitral valve thrombosis in idiopathic hypereosinophilic syndrome: a case report and review of the literature. J Heart Valve Dis 2006;15:721-5. Epub 2006 Oct 19. 